\title{
A PROBLEMATIZAÇÃO COMO POSSIBILIDADE AVALIATIVA
}

\section{PROBLEMATIZATION AS A POSSIBILITY OF EVALUATION}

\author{
GARLET, Francieli Regina \\ francieligarlet@yahoo.com.br \\ Universidade Federal de Santa Maria (UFSM) \\ CARDONETTI, Vivien Kelling \\ vicardonetti@gmail.com \\ Universidade Federal de Santa Maria (UFSM) \\ OLIVEIRA, Marilda Oliveira de \\ marildaoliveira27@gmail.com \\ Universidade Federal de Santa Maria (UFSM)
}

\begin{abstract}
RESUMO Propomo-nos neste artigo pensar o cenário contemporâneo e a produção de subjetividades neste espaço tempo, bem como, elencar alguns pontos que nos incitaram a trazer a problematização como possibilidade avaliativa. A partir de Agamben (2009) e outros autores traçamos as linhas que compõem o espaço e tempo contemporâneo, pensando também a produção das subjetividades neste contexto. Alguns pontos sobre a avaliação são tratados a partir de Zabala (1998), e a partir de Foucault (2004) pensamos o conceito de problematização, esboçando a partir deste algumas possibilidades para pensar a avaliação e a própria educação no contexto contemporâneo.
\end{abstract}

Palavras-chave: Avaliação. Contemporaneidade. Problematização.

ABSTRACT Through this paper we discuss the contemporary scenario and subjectivities' production on this time-space, and we also list some points which incited us to bring problematization as a possibility of evaluation. Starting on Agamben (2009), and other autors we trace the lines which compose contemporary space and time, thinking too the subjectivities' production on this context. Some points about evaluation are treat with the help of Zabala (1998) and through Foucault (2004) we think about the concept of problematization, sketching some possibilities to think about evaluation and also about education on the contemporary context.

Key Words: Evaluation. Contemporariness. Problematization. 


\section{INTRODUÇÃO}

Pensamos, com esta escrita do artigo, que cortes e linhas de fuga são possíveis ou necessários nos processos avaliativos a partir do cenário contemporâneo e da produção de subjetividades neste espaço tempo. Estudamos, enquanto grupo de orientandos do Programa de Pós-Graduação em Educação, na linha de pesquisa LP4: Educação e Artes, especificamente nas disciplinas de Leitura Dirigida e Prática de Pesquisa, parte da bibliografia do filósofo francês Gilles Deleuze, e temos pensado sobre as possibilidades que os conceitos e o próprio estilo de escrita do autor, sugerem para revermos a educação, a docência, a aprendizagem e nossas pesquisas nesta área. É a partir desta perspectiva que estudamos a avaliação neste artigo, em especial a problematização como possibilidade avaliativa, a partir do Q de questão do Abecedário de Gilles Deleuze (1988/1989) e de Foucault (2004).

Nesta perspectiva, convidamos também a se fazerem presentes autores que tratam da contemporaneidade a partir de alguns de seus escritos. Bauman (2007), Veiga Neto (2002) e Agamben (2009) partem de um espaço e tempo líquido, fluído e que se modifica e nos escapa a todo o momento, no qual a sensação é de que o contemporâneo se configura como encontros nos quais estamos sempre atrasados. Autores que abordam a subjetividade, Guattari e Rolnik (2010), nos auxiliam a pensar o indivíduo neste contexto contemporâneo, o modo com que ele é afetado por este contexto, e como é produzido nesta relação.

Dentre autores que se aprofundam no tema da avaliação, Sacristán (1998), Zabala (1998), Pimentel (2009) e Tourinho (2010) contribuem para o mapeamento do que se tem pensado sobre este assunto na educação, de modo geral, e na educação das artes visuais, de modo específico.

Alguns questionamentos se presentificaram no decorrer da escrita, e a partir deles, intentamos movimentar nosso pensamento, não com vistas a respondê-los, mas estendê-los, prolongá-los, problematizá-los, pois é nesse sentido que o 
questionamento se faz potente, quando somos capazes de ir além de uma única resposta que venha a supri-lo, quando somos capazes de fazer com eles uma cartografia que se estende por rizoma, e não linha reta, e traçar um campo de problematização cuja intenção é a própria movimentação e não um produto final.

\section{DE ONDE FALAMOS...}

A escrita sobre este tema se dá a partir de uma humilde aproximação a alguns escritos sobre avaliação entrelaçadas a autores que temos estudado, e de inquietações e questionamentos que se dão perante alguns pontos que se esboçam nestes entrecruzamentos.

Através das lentes do pós-moderno, entendido por Veiga Neto (2002) enquanto esta multiplicidade de tendências (artísticas, filosóficas, científicas) que não se pautam em metanarrativas e representações, entendemos a avaliação como algo que nos produz enquanto nos avalia, e enquanto avaliamos. Isso se dá a partir de um conjunto de regras determinadas pelo tempo e espaço nos quais estamos inseridos. A avaliação é produzida em função das condições de emergência que a solicitam. Como afirma Veiga Neto (2002, p. 31), "é o olhar que botamos sobre as coisas que, de certa maneira, as constitui. São os olhares que colocamos sobre as coisas que criam os problemas do mundo".

Na condição pós-moderna não cabe a procura por um ponto fixo a partir do qual podemos conhecer a realidade. Nessa perspectiva, produzimos a realidade com o nosso movimento, e

em cada parada no máximo conseguimos nos amarrar às superfícies. E aí construímos uma nova maneira de ver o mundo e com ele nos relacionarmos, nem melhor, nem pior do que outras, nem mais correta nem mais incorreta do que outras (VEIGA NETO, 2002, p. 33-34).

O movimento permite que não fiquemos em um mesmo lugar a ponto de criar raízes profundas e difíceis de desprender. Com ele criamos raízes rasas, pois é na superfície que o movimento encontra o que the interessa, e dela se desprende sempre que sente necessidade. Seu combustível é o questionamento, a 
problematização, que the arranca das certezas, que sabemos provisórias, e the permite estender-se em várias direções se conectando a outras possibilidades, a ponto de produzir rizoma ${ }^{1}$.

A tradição ainda tem um peso muito grande, e o esforço em manter a estrutura de sua verdade única, muitas vezes tira a energia que poderia ser utilizada para locomoção, para fazê-la vazar, e criar outras possibilidades de vida com o que o espaço tempo em que vivemos nos oferece. A perspectiva pós-moderna nos permite utilizar diferentes ferramentas - sem uma preocupação com uma verdade única e universal - para nos movimentarmos, produzirmos nossa realidade e nossas verdades contingentes. Não se trata de negar ou eliminar toda e qualquer raiz, tampouco de viver suspenso, mas sim de desprender uma raiz aqui, e conectar com outra acolá, de produzir conexões com as solicitações do que vivemos em nosso cotidiano, sem hierarquizações, nem dualidades (melhor ou pior) permitindo-nos maneiras singulares de subjetivá-las.

\section{O TEMPO DO QUAL SOMOS CONTEMPORÂNEOS E AS POSSIBILIDADES AVALIATIVAS QUE PERMEIAM OS ESPAÇOS EDUCATIVOS NESTE CENÁRIO...}

Buscamos mapear aqui alguns pensamentos sobre o contemporâneo e sobre o tempo do qual somos contemporâneos para, a partir daí, estabelecer algumas conexões com o que temos pensado/estudado sobre avaliação.

Segundo Agamben (2009, p. 59) a contemporaneidade "é uma singular relação com o próprio tempo, que adere a este e, ao mesmo tempo, dele toma distâncias", portanto, um encontro no qual estamos sempre atrasados, ou, um

1 O rizoma é entendido aqui a partir de Deleuze e Guattari (1995) como uma extensão superficial ramificada em todos os sentidos. Em um rizoma, qualquer um de seus pontos pode se conectar a outro, não seguindo uma ordem (como é o caso de um sistema arbóreo que dispõe de uma unidade central e procede por dicotomia). A árvore é decalque, o rizoma é mapa. Mas é importante salientarmos que não se trata de um novo dualismo, visto que, como os próprios autores mencionam (DELEUZE; GUATTARI, 1995, p. 31), "existem nós de arborescência nos rizomas" que os estratificam, e "empuxos rizomáticos nas raízes" que fazem com que ela se estenda e faça conexões. 
encontro com o que nos escapa, ou ainda, como o próprio autor coloca, um compromisso no qual somos pontuais, mas no qual só nos cabe a opção de faltar. Um limiar tênue entre passado e futuro, no qual o presente parece ser inexistente.

O consumo e a moda fugaz, parecem se interligar e emaranhar em torno de si uma série de questões a partir das quais tem se pensado sobre o tempo do qual somos contemporâneos - o mundo líquido moderno - e como temos sido produzidos neste contexto. O consumo parece não se deter ao consumo dos produtos em si, e se alastra para um consumo simbólico de nossas próprias relações cotidianas - ou quem sabe, nossas relações é que tomaram a posição de produtos consumíveis e muitas vezes descartáveis. A moda, por sua vez, se configura como afirma Agamben (2009, p. 67), enquanto algo "constitutivamente adiantado a si mesmo e, exatamente por isso, também sempre atrasado" tendo "sempre a forma de um limiar inapreensível entre um 'ainda não' e um 'não mais'”, assim, aliada a ideia de consumo, parece manter o desejo pela novidade, diminuindo o intervalo de tempo entre adquirir um produto e descartá-lo.

O mundo líquido moderno de que trata Bauman (2007) se esboça nestas vias, e nele o indivíduo sente a necessidade de estar sempre atento, pois suas estratégias e ações podem se tornar obsoletas em um piscar de olhos, e ele precisa estar sempre em movimento, tomando diferentes posições, no intuito de não ser deixado para trás.

Neste tempo, do qual somos contemporâneos, não cabe a busca de uma identidade fixa, nem da experiência enquanto acúmulo, como algo que nos proporciona segurança de ação por esta ter tido sucesso no passado. A incerteza está em cena, nos provocando a sempre estar buscando novas estratégias e posicionamentos, pois tudo muda muito rápido, as situações mudam e nossos medos, por sua vez, se dão em torno de

ser pego tirando uma soneca, não conseguir acompanhar a rapidez dos eventos, ficar para trás, deixar passar as datas de vencimento, ficar sobrecarregado de bens agora indesejáveis, perder o momento que pede mudança e mudar de rumo antes de tomar um caminho sem volta (BAUMAN, 2007, p. 8). 
O sujeito, porém, pode até "odiar o seu tempo, mas sabe, em todo caso, que Ihe pertence irrevogavelmente, sabe que não pode fugir ao seu tempo" (AGAMBEN, 2009 , p. 59). Somos produzidos pelo nosso tempo, no caso, constantemente determinados pelos discursos que são estabelecidos e postos em circulação por uma enunciação coletiva e seus regimes de verdade. Consumimos a subjetividade ${ }^{2}$ que se produz nestes agenciamentos.

Como afirmam Guattari e Rolnik:

evidentemente, um indivíduo sempre existe, mas apenas enquanto terminal; esse terminal individual se encontra na posição de consumidor de subjetividade. Ele consome sistemas de representação, de sensibilidade, etc., os quais não têm nada a ver com categorias naturais universais (GUATTARI; ROLNIK, 2010, p. 41, grifos dos autores).

Os discursos que produzem as subjetividades veiculam a possibilidade de serem repetidos tal como o recebemos e assim serem reforçados, ou, podem ser singularizados, criando resistências que permitem a partir do que se tem em mãos inventar possibilidades de singularização ${ }^{3}$. Pertencemos irrevogavelmente ao nosso tempo, mas isso não impede de criarmos, nos discursos nele produzidos, brechas para problematizá-lo, e para provocar um pequeno desvio, de recusa à subjetivação seriada que nos é oferecida e a qual muitas vezes aceitamos sem pestanejar, e de criação de "modos de subjetivação originais e singulares" (GUATTARI; ROLNIK, 2010 , p. 51). E para que estes últimos vinguem, os indivíduos "devem criar seus próprios modos de referência, suas próprias cartografias, devem inventar sua práxis

2 Guattari e Rolnik (2010, p. 40) fazem uma observação quanto aos termos "indivíduo" e "subjetividade". Para os autores "os indivíduos são o resultado de uma produção de massa. 0 indivíduo é serializado, registrado, modelado. [...] A subjetividade não é passível de totalização ou de centralização no indivíduo. Uma coisa é a individuação do corpo. Outro é a multiplicidade dos agenciamentos da subjetivação: a subjetividade é essencialmente fabricada e modelada no registro do social".

3 Segundo Guattari e Rolnik o modo com que as pessoas vivem a subjetividade "oscila entre dois extremos: uma relação de alienação e opressão, na qual o indivíduo se submete à subjetividade tal como a recebe, ou uma relação de expressão e de criação, na qual o indivíduo se reapropria dos componentes da subjetividade, produzindo um processo que eu chamaria de singularização" (GUATTARI; ROLNIK, 2010, p. 42). 
de modo a fazer brechas no sistema de subjetividade dominante" (GUATTARI; ROLNIK, 2010, p. 58). Produzir pequenos orifícios no cano, e provocar o vazamento, para outras direções, do fluxo que antes se dava em uma única direção. Um exercício de afirmação de uma posição singular, articulada a outros processos de singularização, que resista à nivelação da subjetividade (GUATTARI; ROLNIK, 2010).

Em que a educação e a própria avaliação podem contribuir neste caso? Podem contribuir tanto para o nivelamento da subjetividade - como é o caso de um ensino que quer que o estudante se adapte a ele - como podem contribuir para a escuta das singularidades e das possibilidades de vida que podem ser criadas a partir daí, e para a problematização dos processos de subjetivação que nos assediam cotidianamente. Conforme Bauman (2007, p. 22),

em 1989, Richard Rorty definiu como objetivos desejáveis e realizáveis dos educadores as tarefas de 'agitar os garotos e instigar dúvidas' nos estudantes sobre as imagens que eles têm de si e da sociedade a qual pertencem.

Instigá-los a problematizar, a movimentar seu pensamento acerca do mundo em que vivem. Se estes objetivos, já naquela época, eram apontados como desejáveis pela educação, o que se tem pensado, e o que temos observado desde então com relação à própria avaliação?

Embora saibamos que "as práticas de avaliação mudam com o tempo, assim como mudam as nossas maneiras de pensar o ensino, as abordagens que escolhemos e os focos que privilegiamos em sala de aula" (TOURINHO, 2010, p. 2095), a avaliação tradicional caracterizada como individual, competitiva e classificatória ainda está muito presente em nosso cotidiano.

Neste sentido, Sacristán (1998) coloca uma questão pertinente: por que formas de avaliar que não se aconselham há muito tempo continuam sendo praticadas massivamente? Seria a pressão de informar o que o estudante aprendeu? - que muitas vezes deixa de lado o "como" o estudante está aprendendo; ou a justificativa de utilizá-la para que se mantenha a ordem? Ou será que é para exercer a autoridade e manter uma superioridade frente aos estudantes? Seria um 
comodismo metodológico? Falta de encantamento pelas condições trabalhistas em que se situam? Uma série de outras questões poderiam se instalar aqui. Seguimos pontuando mais algumas considerações.

A perspectiva avaliativa tradicional coloca sobre o estudante o peso de ter de triunfar até a faculdade, de passar na peneira, de ser o melhor - no caso, o que melhor se adapta ao seu ensino árvore, linear. Ela nem sempre considera as singularidades, os movimentos dos estudantes, e muitas vezes corta as possibilidades do estudante de aprender ao seu tempo, de retornar, de questionar, de aprender com encantamento.

O professor, neste sentido, muitas vezes se vê preso às raízes longas de um currículo baseado na preocupação com o acesso do estudante ao ensino superior; por vezes se sente confortável nesta posição, por saber exatamente o que ensinar, o que solicitar em uma avaliação e que perfil de estudante deve formar. Por vezes se vê amarrado, e desafiado a sair desta zona de conforto, criando uma resistência, não no sentido de confrontar este sistema, mas de criar possibilidades de vida em meio ao que os fios destas amarras oferecem como possibilidade de escape. Nesta fuga, pode perceber através da escuta e da observação, outras possibilidades de avaliar e cartografar seu processo enquanto docente, avaliando seu próprio trabalho e o modificando em função das solicitações do grupo. Como aponta Sacristán (1998), a avaliação para além de comprovar a eficácia do professor ou da instituição, pode ser um instrumento para buscar as melhores maneiras de desenvolver 0 processo de ensino/aprendizagem a partir das singularidades. Mesmo que comumente seja voltada ao estudante, a avaliação pode abranger outras instâncias na escola. $\mathrm{Na}$ relação com os estudantes, assim como eles também não permanecemos os mesmos, estamos em processo, e é necessário que também nos avaliemos enquanto condutores/executores das nossas aulas.

Segundo Pimentel (2009), na contemporaneidade a avaliação tradicional e a avaliação formativa são as posturas avaliativas mais adotadas. A avaliação tradicional, como já mencionamos anteriormente, configura-se como uma ação 
individual, competitiva e classificatória, cujo objetivo central é o triunfo do estudante até a universidade; neste sentido, como afirma Pimentel (2009, p. 72) ${ }^{4}$, "São bons/boas alun@s @s que conseguem se adaptar; não é o ensino que se adapta às diferenças d@s alun@s". Na concepção formativa, a avaliação é uma ação coletiva, investigativa, de diagnóstico, em que tanto professores quanto estudantes são agentes ativos do processo educativo. Neste sentido, busca-se a partir desta perspectiva uma avaliação cujo objetivo é conhecer para auxiliar, para favorecer a melhora de algo antes que se conclua o processo. É realizada por meio de procedimentos informais, relacionais, possui um caráter contínuo e está mais centrada na intenção pela qual é realizada e pelo uso que se faz dos dados recolhidos do que da própria técnica empregada (SACRISTÁN, 1998).

A avaliação formativa, proposta por Zabala (1998), no lugar de fazer uma classificação dos conteúdos por matérias, como comumente é realizada pela forma de ensino tradicional, faz uma abordagem a partir das tipologias dos conteúdos que ele denomina: factuais, conceituais, procedimentais e atitudinais. Segundo o autor,

\begin{abstract}
os conteúdos de aprendizagem a serem avaliados não são unicamente conteúdos associados às necessidades do caminho para a universidade. Será necessário, também, levar em consideração os conteúdos conceituais, procedimentais e atitudinais que promovam as capacidades motoras de equilíbrio e de autonomia pessoal, de relação interpessoal e de inserção social (ZABALA, 1998, p. 197).
\end{abstract}

Nesta perspectiva, os conteúdos que ele define como factuais, são aqueles relacionados aos fatos - datas, nomes, acontecimentos, localizações - ou seja, dados descritivos e concretos que, segundo o autor, são melhor entendidos quando relacionados aos conteúdos conceituais. Já estes são os que exigem a compreensão do fato, indo além da sua memorização, envolvendo atividades um pouco mais complexas, incluindo um processo de elaboração e construção pessoal do conceito, que por sua vez jamais está acabado, tento em vista que as relações

\footnotetext{
${ }^{4} \mathrm{O}$ '@' é utilizado pela autora Lúcia Gouvêa Pimentel em seus escritos como uma forma de se referir tanto ao gênero masculino como ao feminino ao mesmo tempo.
} 
em que vai sendo convidado, e as conexões que vai produzindo, vão ampliando seu entendimento.

Os conteúdos procedimentais são aqueles que levam em consideração a ação ou conjunto de ações, envolvendo assim o aprendizado de regras, técnicas, destrezas, habilidades, estratégias, procedimentos, a partir do exercício, do fazer e do pensar sobre a própria atividade. Já os conteúdos atitudinais, versam sobre os valores, as atitudes e as normas. Tendo em vista que as atitudes de outras pessoas intervêm como contraste ou modelo para as nossas e nos persuadem ou nos influenciam sem que em muitos casos a problematizemos, a aprendizagem de conteúdos atitudinais supõe conhecimento e uma problematização sobre os possíveis modelos, que implica uma tomada de posição, e uma constante revisão e avaliação da própria situação. Em sala de aula estes conteúdos podem ser avaliados a partir da escuta e da observação diária.

Estas definições em tipologias são apenas para melhor analisá-las, pois elas não se dão de maneira separada. Como o próprio autor comenta "todo conteúdo, por mais específico que seja, sempre está associado e, portanto, será aprendido junto com conteúdos de outra natureza" (ZABALA, 1998, p. 40).

Estas tipologias dos conteúdos elencadas por Zabala (1998) auxiliam o professor, em seu próprio planejamento, a diversificar as maneiras pelas quais aborda determinado conteúdo curricular. Permite-se assim que ele avalie diferentes instâncias do desenvolvimento do estudante e torne sua aula mais dinâmica, evitando cair na mesmice de uma aula puramente expositiva, cuja avaliação se dá numericamente em torno das alternativas que o próprio professor oferece, e que costumam caber em cinco opções de escolha (a, b, c, d, e). Aliás, só podemos avaliar algumas destas tipologias através da observação e da escuta diária, e o importante não é só efetuar esta observação e esta escuta, mas sim perceber, através delas, as singularidades.

Muitas vezes, devido ao grande número de estudantes em uma mesma turma, não conseguimos perceber tudo o que acontece, mas sempre captamos, escutamos, observamos alguma coisa. Fica em nossas mãos o critério do que fazer com esses elementos percebidos; podemos fingir não ter visto nada, reprimir, fugir, 
mas também podemos traçar a partir daí outras possibilidades. A escuta das singularidades acontece, portanto, quando o foco não se limita as avaliações finais, e se debruça no próprio processo, nas nossas relações com os estudantes a cada aula, a partir daquilo que permite nos modifiquemos no caminho, que nos solicitam alterações quanto aos nossos planejamentos iniciais, e que nos presenteiam com outras vias possíveis para aquele caminho que pensávamos ter uma direção única e tranquila.

Assim, a avaliação no lugar de se limitar às alternativas de respostas ou a produtos finais, pode funcionar como termômetro que nos auxilia a perceber o momento de abrir espaço para que outros questionamentos surjam e atravessem nosso trabalho, nos desafiando a arriscar outros caminhos.

\subsection{AVALIAÇÃO EM ARTES VISUAIS}

Situamo-nos enquanto pesquisadoras na linha de pesquisa educação e artes, e por este motivo trazemos alguns pontos para discutir a avaliação em artes visuais.

Pimentel (2009) afirma que, por muito tempo a arte não foi considerada como área de conhecimento e com esta justificativa, portanto, não era avaliada. Nesta visão fechada na livre expressão, esquecia-se que a arte possui vários âmbitos de conhecimento, não só por sua história, seus conceitos, mas também pelas problematizações que podem gerar frente às nossas vivências.

$\mathrm{Na}$ educação das artes visuais, a postura epistemológica que vem sendo assumida se dá a partir da cultura visual, que visa pensar/questionar as imagens que circulam e interpelam nosso dia a dia; imagens que nos produzem a partir dos discursos veiculados por elas, e que na maioria das vezes carecem de problematização.

A partir dos encontros com imagens também aprendemos a tomar um posicionamento no espaço e no tempo em que vivemos. Segundo Brea (2010, p. 115, tradução livre) "os elementos de ordem visual têm crescente importância nos processos contemporâneos de socialização e subjetivação", assim, as imagens funcionam como materialidade de enunciados discursivos. 
As tecnologias têm favorecido a produção e disseminação de imagens. As redes sociais, por exemplo, favorecem que nossas imagens criem conexões com imagens de outros indivíduos, e neste entrecruzamento, como afirma Hernández, fazemos nossos os significados "que formam parte de outros relatos e referências culturais" (HERNÁNDEZ, 2011, p. 34). Nestas apropriações de sentidos, vamos assumindo ou produzindo subjetividades; assim as imagens têm muito a dizer de nós e da relação com o mundo em que vivemos.

Em nosso dia a dia, geralmente, não dedicamos tempo para pensar sobre as imagens que permeiam nossos percursos. A educação das artes visuais na perspectiva da cultura visual pode auxiliar na problematização destas imagens de modo que possamos estender as possibilidades de pensá-la, com o demoramento necessário, para que haja uma apropriação e uma singularização dos discursos que elas veiculam.

Se formos pensar o que pode ser avaliado em artes visuais, segundo as tipologias dos conteúdos propostas por Zabala (1998), podemos citar a partir dos conteúdos factuais, o conhecimento de nomes de artistas, do local onde nasceram e trabalharam, dos fatos históricos relacionados as suas obras. Porém, é necessário que os conteúdos factuais estejam conectados aos conteúdos conceituais, que se referem aos conceitos elencados pela própria obra do artista, ou conceitos que podemos pensar a partir de suas obras, relacionando-os às nossas vivências e os utilizando como ferramentas para pensar nosso cotidiano. Os conteúdos procedimentais, que visam trabalhar as ações e o pensar sobre estas ações, podem incluir a escrita, a pesquisa, a produção de trabalhos artísticos, que não envolvam um fazer por fazer, mas sim um fazer pensado, elaborado. Os conteúdos atitudinais, que se referem às atitudes do estudante, podem ser avaliados através da escuta e da observação dos posicionamentos tomados pelos estudantes frente aos discursos que as imagens veiculam.

A problematização pode permear todas as tipologias, pois, se pensarmos os conteúdos factuais, estes se entrelaçam com os conceituais, que por sua vez podem ser utilizados como ferramentas para problematizar o cotidiano. Se pensarmos os procedimentais, estes envolvem um pensar que pode ser disparado por uma 
problematização. Por fim, os atitudinais podem ser abordados a partir do constante questionamento dos posicionamentos que tomamos em nosso cotidiano.

A avaliação destes conteúdos pode se dar na observação e na escuta do que acontece no dia a dia escolar, buscando conhecer as necessidades do grupo de estudantes de modo a produzir estratégias para auxiliá-los, e podem também estar funcionando como disparadores para questionamentos da própria prática do professor, auxiliando-o a pensar em redimensionamentos nos planejamentos iniciais.

Segundo Tourinho (2010, p. 2099-2100),

a avaliação formativa tem sido recomendada nas novas propostas curriculares de arte, já que visa acompanhar o aluno no dia a dia da escola, busca conhecê-lo e reconhecer suas oscilações, ou seja, seus ganhos, perdas, dificuldades e facilidades. Assim, a avaliação formativa leva em conta resultados não esperados ou planejados, porém, significativos e valiosos para ajudar alunos e professores na tarefa de aprender/ensinar.

Em Artes ou em qualquer outra área do conhecimento a avaliação é necessária não só para saber o quanto o estudante está aprendendo, mas sim de que forma ele aprende, qual o seu tempo. A avaliação auxilia o professor a dar o próximo passo, a atentar para os imprevistos, e a produzir os desvios necessários para que seja possível inventar outras possibilidades para tornar os conteúdos curriculares mais próximos da vida dos estudantes, e assim mais leves e instigantes.

\section{AVALIAR PARA MOVIMENTAR O PENSAMENTO...}

Não buscamos com esta escrita tecer uma metodologia avaliativa, que se siga à risca, mas buscamos pensar a problematização como uma forma de vir a provocar, no cotidiano escolar e fora dele, o movimento do pensamento, não só o nosso, enquanto docentes, mas também o dos estudantes.

Deleuze, em entrevista prestada à jornalista Claire Parnet (1988/1989), estabelece algumas diferenças entre questão e interrogação. Segundo ele só uma 
destas opções permite a criação de problemas. Ele cita a mídia, e a televisão habitual, enquanto algo em que se produzem apenas interrogações, que se fecham na opinião das pessoas. Já o questionamento não se fecha em uma opinião, mas sim provoca a transformação de questões em outras questões, ou provoca conexões com outras questões que possam dialogar com elas e produzir um campo de problematização. Segundo o autor, na mídia habitual e nas conversas correntes, ficamos geralmente no nível das interrogações. A problematização envolve um estiramento da questão, ou seja, não se resume a sua solução. A questão age como um disparador que a prolonga, podendo gerar outros questionamentos e a invenção de outras direções que não se resumem ao que já existe, a um desvelamento, e sim permitem a criação de outras possibilidades a serem vividas.

As interrogações e as perguntas são apenas conversas, não têm importância. A problematização provoca um disparador. Aprofunda o olhar. A problematização é uma maneira de lançar sobre objetos e situações comuns, obras de arte, imagens e visualidades em geral, outro direcionamento. A problematização, diferente da interrogação, exige de nós um distanciamento, necessário para que haja uma desnaturalização, uma desconstrução de noções como verdadeiro/falso, certo/errado, bonito/feio. Esse distanciamento nos permite repensar o que é normativo, questionar de onde surgiu. Como essa normatividade não é uma verdade absoluta, mas algo criado a partir das vivências, ela é algo criado por nós em certa época sob certa circunstância, criado socialmente, algo que perderá seu significado com a passagem do tempo. O distanciamento normalmente implica um afastamento temporal, pois a passagem do tempo traz a desnaturalização e o desprendimento necessário para enxergarmos a produção daquele determinado momento histórico como apenas uma produção, e não como uma verdade absoluta. Foucault (2004), a partir do conceito de problematização, sugere que façamos essa desnaturalização diariamente, enxergando os padrões não mais como referências, uma vez que, não havendo verdade, não podemos nos guiar por nada então produzido. Problematizar é desprender-se, criando uma distância crítica que nos permita não sermos mais engolidos nem escravizados pelo que produzimos: é ter consciência de que nós 
produzimos essas "verdades", e que, sendo assim, verdades únicas e universais de fato não existem. Foucault define o termo da seguinte forma:

Problematização não quer dizer representação de um objeto preexistente, nem tampouco a criação pelo discurso de um objeto que não existe. É o conjunto das práticas discursivas ou não discursivas que faz alguma coisa entrar no jogo do verdadeiro e do falso e o constitui como objeto para o pensamento (seja sob a forma da reflexão moral, do conhecimento científico, da análise política, etc.) (FOUCAULT, 2004, p. 242).

Dar ao estudante um problema pronto para que resolva não é problematizar, pois não movimenta o pensamento do estudante, que apenas resolve o que está ali, o que é dado, não o provoca a estabelecer conexões com outras instâncias, não o provoca a produzir outras questões, não the permite inventar o problema. Segundo Deleuze, a criação de problemas não está ligada à busca por sua solução, mas trata-se mais de "encontrar o problema e colocá-lo" (DELEUZE, 1999, p. 9). Colocar o problema não é simplesmente descobri-lo, mas inventá-lo. Conforme o autor, "a descoberta incide sobre o que já existe, atualmente ou virtualmente; portanto cedo ou tarde ela seguramente vem. A invenção dá o ser ao que não era, podendo nunca ter vindo" (DELEUZE, 1999, p. 9).

A problematização é podada quando as questões, ou melhor, as interrogações que fazemos - a nós mesmos, ou aos estudantes - se resumem a respostas do tipo sim ou não. Também perde potência quando a fechamos numa única possibilidade de se desenvolver, tentando trazê-la, a todo custo, de volta, quando ela assume direções que não esperávamos ter. A problematização precisa de tempo para acontecer, e se torna inútil quando não damos a ela a devida atenção, que é o que permite com que ela opere em nosso pensamento, e o violente, provocando-o a pensar.

5 PARA CONCLUIR: ALGUNS PONTOS QUE QUIÇÁ SE PROLONGUEM PARA ALÉM DESTA ESCRITA 
Fizemos a partir desta escrita um apanhado do que se tem pensado sobre o mundo do qual somos contemporâneos (AGAMBEN, 2009), sobre como temos nos produzido neste cenário e sobre o que se tem pensado sobre a avaliação (ZABALA, 1998) para, a partir daí, trazer alguns pontos que nos provoquem a trazer a problematização (FOUCAULT, 2004) como possibilidade, não só de avaliar, mas também de produzir outras possibilidades de vida, com o que nos é oferecido pelas condições do espaço tempo em que vivemos.

O mundo líquido moderno e o próprio consumo, tem nos deixado com sede de novidades, do próximo desejo que virá substituir aquele que temos hoje. Desejos que consumimos tal qual recebemos, sem problematizá-los. A problematização torna-se assim uma ferramenta necessária para produzirmos maneiras singulares de subjetivação.

Falamos aqui na criação de possibilidades de vida, e isso, precisamos deixar claro, não se resume à próxima possibilidade oferecida pelo mercado. Trocar uma metodologia de ensino por outra emergente, sem a devida problematização, pode ser tão problemático quanto continuar na mesma. A criação de outras possibilidades de vida requer resistência, mas isso não quer dizer que temos que confrontar tudo o que nos é colocado pelo sistema. Cabe-nos, sim, uma resistência, que nos permita conviver, ou sobreviver com o que temos, problematizando e produzindo com isso pequenas rachaduras a partir das ferramentas que temos em mãos (inclusive as oferecidas pelo sistema). Trata-se de escutar as singularidades que encontramos no espaço escolar, para a partir daí tecer uma metodologia singular, que dê conta de cartografar as necessidades que se criam todos os dias nestes ambientes. Trata-se de estar sempre problematizando, produzindo e lançando questões que deem conta de movimentar o pensamento; trata-se de questionar nossas certezas, fazendo brotar de seus restos outras possibilidades de vida escolar, que não o consumo de ideias prontas, mas apropriação destas, e criação de possibilidades singulares.

Outra questão que nos parece pertinente trazer nestas linhas finais (que se pretendem disparadoras de outras questões) é o modo como nos relacionamos com a avaliação, como a consumimos e como ela nos produz. Não há como fugirmos da avaliação, ela permeia nosso dia a dia, e o modo com que nos relacionamos com ela 
pode tanto funcionar como um entrave (o que pode acontecer tanto no caso de uma aprovação que pode nos acomodar nas nossas certezas, como de uma reprovação que pode inibir, nos diminuir a potência de agir) como nos lançar as infinitas linhas de um rizoma que se estende em diferentes direções.

Ao comungarmos com uma perspectiva pós-moderna onde não há uma única verdade, e onde as certezas são tomadas como provisórias, os diferentes pontos de vista sob os quais somos avaliados, nos permitem, ao invés de um retorno para reproduzir ou reforçar um saber, tomar os pontos de uma avaliação como disparadores de outras direções, como um ampliador de possibilidades de pensar, repensar o que fazemos, ou temos pensado até então sobre determinado assunto. $O$ retorno a algo, pensado nesta direção se oferece não para corrigir, conforme uma forma vigente, nosso modo de pensar, mas sim como abertura, como inauguração de outras tantas maneiras de pensar sobre um mesmo tema, e assim problematizar nossas próprias certezas.

Se não há uma verdade única, várias são as possibilidades de avaliar e vários são os pontos de vista sob os quais somos avaliados. Portanto, nesta perspectiva não cabe tomarmos a avaliação como sentença final, como fomos ensinados pela tradição a entendê-la, mas sim como possibilidade de experimentar direções imprevistas. Nesse sentido, a avaliação pode ser pensada como forma de invenção e de movimento, que nos disparam sempre a produzir outros caminhos. Mas, para que tal movimento aconteça se faz necessário que o nosso posicionamento diante da avaliação que fazem de nós, e perante a avaliação que fazemos do outro seja de escuta, e que perceba, forneça subsídios que lancem outras questões que coloquem em cheque nossas certezas. A avaliação para além de servir enquanto uma sentença de passagem de um ponto a outro, o que é inevitável no sistema no qual estamos inseridos, apresenta nuances que podem ser percebidas e degustadas no processo, no meio do caminho. Pode, portanto, se oferecer a cada vez enquanto algo a ser experienciado, como vias de problematização que nos produzem não apenas enquanto números e letras acumulados no decorrer de nossas vivências, mas também enquanto uma cartografia de experiências que nos acontecem a cada 
vez, disparando possibilidades que ao passo que vão se produzindo, vão também modificando-nos a cada vez.

\section{FRANCIELI REGINA GARLET}

Doutoranda em Educação e Mestre em Educação pela Universidade Federal de Santa Maria (UFSM), RS.

\section{VIVIEN KELLING KARDONETTI}

Doutoranda em Educação pela Universidade Federal de Santa Maria (UFSM), RS.

\section{MARILDA OLIVEIRA DE OLIVEIRA}

Professora do Programa de Pós-Graduação em Educação da Universidade Federal de Santa Maria (UFSM), RS. Coordenadora do GEPAEC - Grupo de Estudos e Pesquisas em Arte, Educação e Cultura, editora da Revista Digital do Laboratório de Artes Visuais.

\section{REFERÊNCIAS}

AGAMBEN, G. O que é o contemporâneo? E outros ensaios. Tradução de Vinícius Nicastro Honesko. Chapecó: Argos, 2009, 92 p.

BAUMAN, Z. Vida líquida. Tradução de Carlos Alberto Medeiros. Rio de Janeiro: Jorge Zahar Ed., 2007, 212 p.

BREA, J. L. Las tres eras de la imagen: Imagen-materia, film, e-image. Madrid: AKAL, 2010, $142 \mathrm{p}$.

DELEUZE, G. Bergsonismo. Tradução de Luiz B. L. Orlandi. São Paulo: Ed. 34, 1999, $144 \mathrm{p}$.

O abecedário de Gilles Deleuze. Direção de Pierre André Boutang. No Brasil, foi divulgado pela TV Escola, Ministério da Educação Tradução e Legendas: Raccord [com modificações] Paris: Éditions Montparnasse, 1988-1989.

DELEUZE, G.; GUATTARI, F. Mil platôs: capitalismo e esquizofrenia. Tradução de Aurélio Guerra e Célia Pinto Costa. Rio de Janeiro: Ed. 34, 1995, 128 p.

FOUCAULT, M. O cuidado com a verdade. In: MOTTA, M. B. (Org.). Ditos e escritos. (Vol. V). Rio de Janeiro: Forense Universitária, 2004, p. 234-245. 
GUATTARI, F.; ROLNIK, S. Micropolítica: cartografias do desejo. 10. ed. Petrópolis, Rio de Janeiro: Vozes, 2010, 327 p.

HERNÁNDEZ, F. A cultura visual como um convite à deslocalização do olhar e ao reposicionamento do sujeito. In: MARTINS, R.; TOURINHO, I. (Orgs.). Educação da Cultura Visual: conceitos e contextos. Santa Maria: Editora da UFSM, 2011, p. 31-49.

PIMENTEL, L. Avaliação em arte: desafios e pressupostos. In: ASSIS, H. L.; RODRIGUES, E. B. T. (Orgs.). O ensino de artes visuais: desafios e possibilidades contemporâneas. Goiânia: SEDUC/GO, 2009, p.71-75.

SACRISTÁN, J. G. A avaliação no ensino. In: SACRISTÁN, J. G.; PÉRES GOMES, A. I. Compreender e transformar o ensino. 4. ed. Tradução de Ernani F. da Fonseca Rosa. Porto Alegre: ArtMed, 1998, p. 295-351.

TOURINHO, I. Retomando um tema delicado: avaliação e ensino de arte. In: $19^{\circ}$ ANPAP, Anais... Cachoeira/Bahia, 2010, p. 2094-2106. Disponível em:

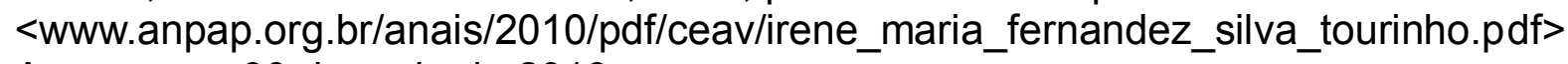
Acesso em: 30 de maio de 2013.

VEIGA NETO, A. Olhares... In: COSTA, M. V. (Org.). Caminhos investigativos: novos olhares na pesquisa em educação. Rio de Janeiro: DP\&A, 2002, p. 23-38.

ZABALA, A. A prática educativa: como ensinar. Tradução de Ernani F. da F. Rosa. Porto Alegre: ArtMed, 1998, 224 p. 